\title{
Video Films in Nursing and Midwifery Teaching - Statistical Study of Dependence
}

\author{
Tsveta Hristova, Despina Georgieva
}

Department of Healthcare, University of Ruse Angel Kanchev, Ruse, 7017, 8 Studentska str., Bulgaria

\begin{abstract}
The paper presents educational videos as an interactive method of teaching nursing and midwifery students. As a part of the methods of online education, educational videos transform the learning content into a practical necessity for the formation ofstudents' professional competencies in the considered medical specialties. Correlation analysis identifies the degree of coherence between the observed features: "training with video films" and "professional competencies formation". Using $\chi^{2}$ statistics, it is decided whether the relationship between two nominal variables is statistically significant and how the strength of the relationship i.e., the extent of the effect, is valued using the coefficients Phi and Cramer's V. The statistical processing of the performed didactic experiment proves a "strong" correlation between the studied features.
\end{abstract}

Keywords - online education, video films, midwives, nurses students, correlation statistical analysis.

\section{Introduction}

E-learning, as a phenomenon in its various forms and aspects, has developed with exceptional dynamics in the field of education over the last decade.

DOI: 10.18421/TEM104-04

https://doi.org/10.18421/TEM104-04

Corresponding author: Tsveta Hristova, Department of Healthcare, University of Ruse Angel Kanchev, Ruse, 7017, 8 Studentska str., Bulgaria

Email: tshristova@uni-ruse.bg

Received: 11 August 2021.

Revised: 08 September 2021.

Accepted: 14 September 2021.

Published: 26 November 2021.

(c) BY-NC-ND (C) 2021 Tsveta Hristova \& Despina Georgieva; published by UIKTEN. This work is licensed under the Creative Commons Attribution-NonCommercial-NoDerivs 4.0 License.

The article is published with Open Access at www.temjournal.com
This trend is an expression of both the growing interest in modernizing education through the inclusion of modern digital forms of learning and teaching.

Among other things, we have to take into account the spread of COVID'19, declared a pandemic by the World Health Organization.

The definition of e-learning has been enriched by the numerous world practices and theoretical studies that cover the diverse aspects of this phenomenon [2], [13].

Video training and training based on it is a powerful tool. It can be used both in formal training and in the process of students' self-preparation.

Video films bring strong interactivity in pedagogical interaction and in the process of assessing students' knowledge [6], [11]. Video films are implemented in a scenario-based training in order to stimulate proper behavior and manipulative techniques to perform certain medical manipulations and procedures [14]. This approach creates more effective learning as the trainee is provided access to specific content, relevant to his needs. The process leads to the personalization of the learning experience and the promotion of lifelong learning.

The power of persuasive influence of images seen on screen - if well motivated, can be "assimilated" by the unconscious tendencies of the viewer and thus generate behavior. According to cognitive psychology, the effect of the impact of the message, received through visual stimuli that individuals remember, is about $20 \%$ of what is heard, $40 \%$ of what is seen and up to $80 \%$ of what is seen and heard, and according to some other studies, people perceive information $83 \%$ visually and $12 \%$ auditory [15]. Researchers report that the influence of films (video films are included in their narrow sense) is achieved through the created visual, sound, editing, structural and content (semantic) models of persuasive influence [2]. 


\section{Exposition}

With the training films made, we focus on the semantic aspect, necessary for the main goal practical training of health care professionals, in the specialty area of Nursing and Midwifery. The film narrative contains the main purpose for which the video film is created (the scientific-methodical resource for training). The meaning conveys a message that carries information with an individual implicit intent for each individual film. The report analyzes the practical training with the use of video films: observation and examination of a normal pregnancy, birth in the first and third period, care for a newborn, supporting seriously ill people with maintaining their hygiene needs using the method of "bed bathing", bandages of head and limbs, prevention of bedsore, and the use of types of injections. The study was conducted in 2019 - 2020 and 2020 - 2021 academic year at the University of Ruse "Angel Kanchev", Faculty of Public Health, Department of Health Care. Participants are divided into two focus groups: Focus group 1 is control, with 146 students; Focus Group 2 is the experimental one with 150 students. The students are from the first and second year of study at the bachelor's degree of the Midwifery and Nursing courses. They cover the age group 19 - 36 years, distributed in equal numbers according to it. The distribution is similar for the other significant group characteristics (education, gender, place of residence). In Focus Group 2, students are also trained in the video film method. They were provided with educational films during the school years from the module "Practical basics of nursing and midwifery care".

The formation of basic professional competencies for the future profession is an important task of the didactic process [8], [14]. In the complex global environment of COVID-19, various didactic methods and tools for training health care professionals are sought and used.

Statistical correlation analysis was used to prove the study [3], [4].

Correlation analysis is a method for analyzing statistical connections and dependencies. The aim is to identify the degree of coherence between two signs. This paper presents a study of the correlation between the observed signs of "video learning" and "formation of professional competencies". It is content conditioned ie., there is a practical explanation. The statistical measure to describe the bonds between two observed variables is the correlation coefficient. It describes the extent to which two sets of values are linearly related, or is a measure of the ties between two variables [1], [5].

\section{Methodology}

Using $\chi^{2}$ statistics, it is decided whether the relationship between two nominal variables is statistically significant and how the strength of the relationship i.e., the extent of the effect, is valued using the coefficients Phi and Cramer'sV. Using $\chi^{2}$, it is determined whether there is a statistically significant connection between two variables, but if it turns out that there is one, it is not possible to determine its strength. This is explained by the fact that the value of $\chi^{2}$ depends on the number of variables in the cross table and the volume of the sample. For this reason, Pearson proposed the coefficient Phi, which is obtained by taking the square root of the value of $\chi^{2}$ and dividing the resulting value by the sample size. The purpose of the new coefficient $\mathrm{Phi}$ is to obtain a visual interpretation of the relations between two variables. The coefficient is in the range between 0 and 1, it is equal to 0 when the two variables are independent, and is equal to 1 when the two variables are completely related to each other. This purpose is not fully achieved, because if one of the two variables has more than two levels, the worth of the coefficient Phi can take values greater than 1 . This disadvantage of Pearson's Phi coefficient was corrected by Kramer. He introduces a new coefficient $V$, which is always between 0 and 1 and serves as a characteristic of the strength of the connection between the two variables [1], [7], [9].

Crosstable 1 shows the joint distribution of Focus Group 1 (control) and Focus Group 2 (experimental), respectively at the beginning and end of the period of the two studied features: "training with video films" and "formation of professional competences ".

An analysis of the data from the cross-table 1 of Focus group 1 was performed in the initial stage of the didactic experiment. The studied indications for better clearness are marked - (training with video films - yes) and successful "formation of professional competencies" (yes). In Focus Group 1, initially, 29 students (19.9\%) worked in their self-preparation with the proposed educational videos and formed the necessary professional competencies according to the lecturers. They represent $87.9 \%$ of all in Focus Group 1, who have also been trained with video films and are $96.7 \%$ of those students who have formed the necessary professional competencies for the profession of Midwife and Nurse. The interpretation of all other data is presented by analogy. 
Table 1. Two-dimensional distribution of the observed variables, Focus group 1 and Focus group 2, at the beginning and at the end of the considered period

\section{Training with video films * Formation of professional} competencies Crosstabulation

\begin{tabular}{|c|c|c|c|c|c|c|}
\hline \multirow{2}{*}{\multicolumn{4}{|c|}{ Focus group }} & \multicolumn{2}{|c|}{$\begin{array}{l}\text { Formation of } \\
\text { professional } \\
\text { competencies } \\
\text { (PCs) }\end{array}$} & \multirow{3}{*}{$\begin{array}{c}\text { Total } \\
113\end{array}$} \\
\hline & & & & \multirow{2}{*}{$\begin{array}{l}\text { No } \\
112\end{array}$} & \multirow{2}{*}{$\begin{array}{c}\text { Yes } \\
1\end{array}$} & \\
\hline \multirow{12}{*}{ 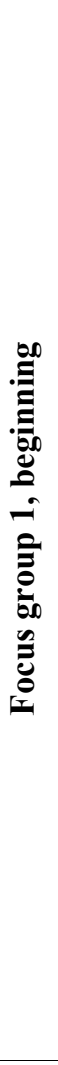 } & \multirow{8}{*}{ 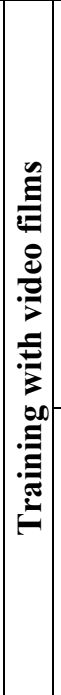 } & \multirow{4}{*}{$\stackrel{0}{9}$} & Count & & & \\
\hline & & & $\begin{array}{l}\text { \% within } \\
\text { Training with } \\
\text { video films }\end{array}$ & $99,1 \%$ &, $9 \%$ & $100,0 \%$ \\
\hline & & & $\begin{array}{l}\% \quad \text { within } \\
\text { Formation of } \\
\text { PCs }\end{array}$ & $96,6 \%$ & $3,3 \%$ & $77,4 \%$ \\
\hline & & & $\%$ of Total & $76,7 \%$ &, $7 \%$ & $77,4 \%$ \\
\hline & & \multirow{4}{*}{$\stackrel{\infty}{\infty}$} & Count & 4 & 29 & 33 \\
\hline & & & $\%$ within & $12,1 \%$ & $87,9 \%$ & $100,0 \%$ \\
\hline & & & $\begin{array}{c}\% \text { within } \\
\text { Formation of } \\
\text { PCs }\end{array}$ & $3,4 \%$ & $96,7 \%$ & $22,6 \%$ \\
\hline & & & $\%$ of Total & $2,7 \%$ & $19,9 \%$ & $22,6 \%$ \\
\hline & \multirow{4}{*}{\multicolumn{2}{|c|}{ Total }} & Count & 116 & 30 & 146 \\
\hline & & & $\begin{array}{l}\% \text { within } \\
\text { Training with } \\
\text { video films }\end{array}$ & $79,5 \%$ & $20,5 \%$ & $100,0 \%$ \\
\hline & & & $\begin{array}{c}\% \text { within } \\
\text { Formation of } \\
\text { PCs }\end{array}$ & $100,0 \%$ & $\begin{array}{c}100,0 \\
\%\end{array}$ & $100,0 \%$ \\
\hline & & & $\%$ of Total & $79,5 \%$ & $20,5 \%$ & $100,0 \%$ \\
\hline \multirow{10}{*}{ 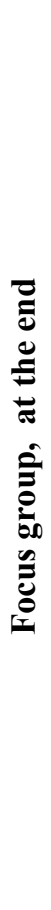 } & \multirow{8}{*}{ 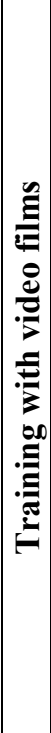 } & \multirow{4}{*}{ ఏ } & Count & 103 & 9 & 112 \\
\hline & & & $\begin{array}{l}\% \text { within } \\
\text { Training with } \\
\text { video films }\end{array}$ & $92,0 \%$ & $8,0 \%$ & $100,0 \%$ \\
\hline & & & $\begin{array}{l}\% \text { within } \\
\text { Formation of } \\
\text { PCs }\end{array}$ & $98,1 \%$ & $22,0 \%$ & $76,7 \%$ \\
\hline & & & $\%$ of Total & $70,5 \%$ & $6,2 \%$ & $76,7 \%$ \\
\hline & & \multirow{4}{*}{$\stackrel{\infty}{\infty}$} & Count & 2 & 32 & 34 \\
\hline & & & $\begin{array}{l}\% \text { within } \\
\text { Training with } \\
\text { video films }\end{array}$ & $5,9 \%$ & $94,1 \%$ & $100,0 \%$ \\
\hline & & & $\begin{array}{c}\% \text { within } \\
\text { Formation of } \\
\text { PCs }\end{array}$ & $1,9 \%$ & $78,0 \%$ & $23,3 \%$ \\
\hline & & & $\%$ of Total & $1,4 \%$ & $21,9 \%$ & $23,3 \%$ \\
\hline & \multirow{2}{*}{\multicolumn{2}{|c|}{ Total }} & Count & 105 & 41 & 146 \\
\hline & & & $\begin{array}{l}\% \text { within } \\
\text { Training with } \\
\text { video films }\end{array}$ & $71,9 \%$ & $28,1 \%$ & $100,0 \%$ \\
\hline
\end{tabular}

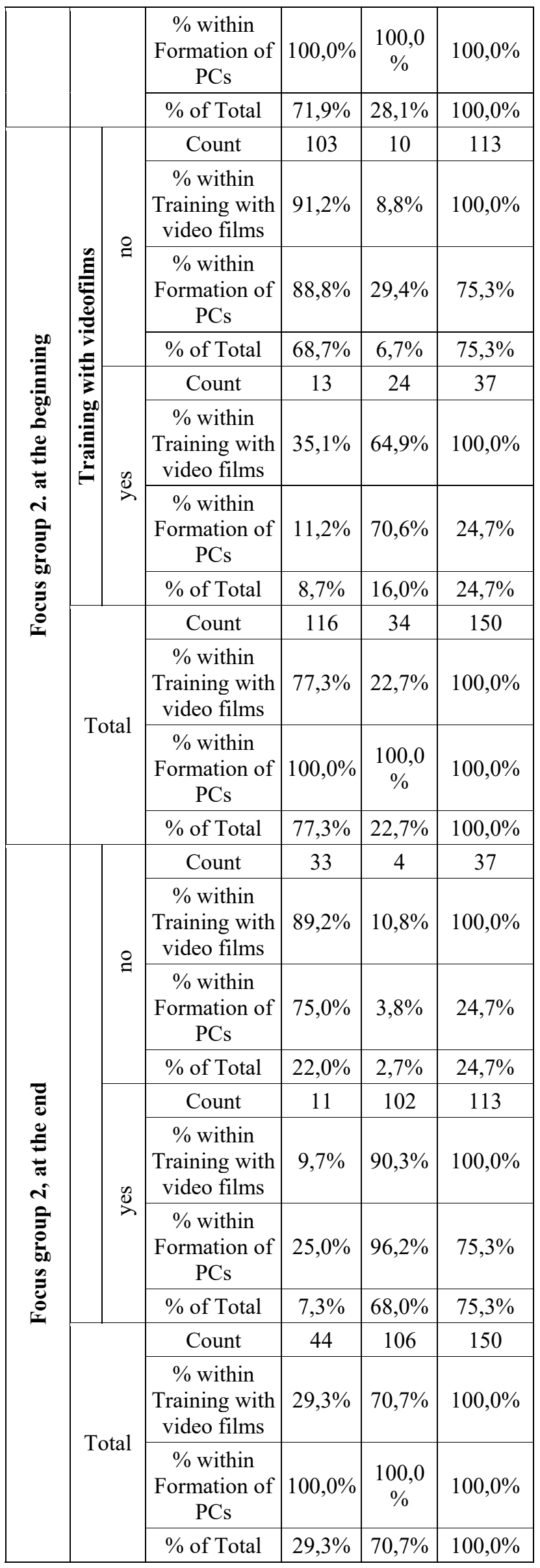


The information, given in Table 1, creates the impression that the students who are trained with video films, according to the lecturers, form the necessary professional competencies for future realization. Students who have not used the methodological resource video-film, show difficulties and omissions in performing basic medical procedures and manipulations.

Future healthcare professionals have to master the techniques of medical manipulation to perfection, acquire fine-tuning and adopt skills to the point of automation before applying them to the patient [15]. At the same time, students are taught to control their feelings and strike a balance between developing technical skills and professional competence. An important construct of the didactic interaction in the formation of practical skills is the participation of the patient. This requires a safe learning environment for students, lecturers and patients [10], [12].

To study the dependence, the strength of the dependence and its statistical significance, the correlation coefficients for nominal traits - Phi and Cramer's V, presented in Table 2, are used.

Table 2. Phi and Cramer's V correlation coefficients and their statistical significance

\begin{tabular}{|c|c|c|c|c|}
\hline \multicolumn{5}{|c|}{ Symmetric Measures } \\
\hline \multicolumn{3}{|c|}{ Group } & Value & Approx. Sig. \\
\hline \multirow{3}{*}{ 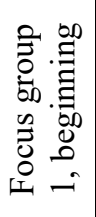 } & \multirow{2}{*}{$\begin{array}{l}\text { Nominal by } \\
\text { Nominal }\end{array}$} & Phi & ,901 &, 000 \\
\hline & & Cramer's V & ,901 &, 000 \\
\hline & \multicolumn{2}{|c|}{$\mathrm{N}$ of Valid Cases } & 146 & \\
\hline \multirow{3}{*}{ 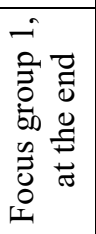 } & \multirow{2}{*}{$\begin{array}{l}\text { Nominal by } \\
\text { Nominal }\end{array}$} & Phi & ,810 &, 000 \\
\hline & & Cramer's V &, 810 &, 000 \\
\hline & \multicolumn{2}{|c|}{$\mathrm{N}$ of Valid Cases } & 146 & \\
\hline \multirow{3}{*}{ 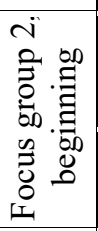 } & \multirow{2}{*}{$\begin{array}{l}\text { Nominal by } \\
\text { Nominal }\end{array}$} & Phi &, 577 & ,000 \\
\hline & & Cramer's V &, 577 &, 000 \\
\hline & \multicolumn{2}{|c|}{$\mathrm{N}$ of Valid Cases } & 150 & \\
\hline \multirow{3}{*}{ 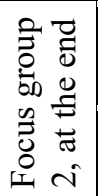 } & \multirow{2}{*}{$\begin{array}{l}\text { Nominal by } \\
\text { Nominal }\end{array}$} & Phi &, 752 &, 000 \\
\hline & & Cramer's V &, 752 &, 000 \\
\hline & \multicolumn{2}{|c|}{$\mathrm{N}$ of Valid Cases } & 150 & \\
\hline
\end{tabular}

The analysis of the data presented in Table 2 shows that for each group the two coefficients coincide. The correlation coefficients in all groups were statistically significant (Approx. Sig $<0.05$ ) and positive. Therefore, there is a statistically significant positive correlation. The connection is extremely strong, almost determined in Focus Group 1, at the beginning, where both correlation coefficients between the characteristics "video training" and "formation of professional competencies" have a value of 0.901. In Focus Group 2, in the initial period of the study, where the coefficients are the smallest (0.577) compared to the others, the coefficient is large enough to define the relation in this group as "strong". The statistical study of the bond between the observed signs of "training with video films" and "formation of professional competencies" shows a "strong" correlation. Midwifery students and nurses, who are also trained in video films, form more successfully the necessary professional competencies for the future profession. The content of the films performs an educational function through:

- provoking the attention;

- the logical-sequence of the action, structuring the narrative, the identification, the topicality and the authenticity of the transmitted facts, with the numerous views and positive evaluation by colleagues.

\section{Disadvantages:}

- Lack of live contact with a lecturer, teacher, colleagues;

- Requires more effort on the part of the teacher to create and distribute the video films;

- Technical problems possibilities (internet, device failure);

- Lack of feedback in self-study.

Against the background of the healthcare crisis related to the extremely insufficient number of healthcare professionals, the education should rely on the use of appropriate didactic methods correlated with the preferences of the students. Modern students are digital generation, receiving information from the Internet through a computer, laptop, tablet, phablet, and smartphone.

\section{Conclusion}

The digital generation of students prefer to visit websites and watch theoretical topics. They think that a video film that they will watch in 5-10 minutes is more impactful, more memorable than reading text in 30 minutes.

Thanks to e-learning environments, allowing the integration of e-resources in a diverse digital format, learners have remote access to them, which facilitates their professional training. Video films also expand the possibilities for self-preparation, as they can use them repeatedly in the learning process at a time convenient for them. Effective acquisition of knowledge will allow trainee nurses and midwives to be able to make interdisciplinary connections related to scientific theoretical facts, to analyze and synthesize information, to make correct judgments, to develop clinical thinking, to transfer theoretical knowledge in practical training, to offer solutions to specific problems, and to associate what has already been learned with new knowledge. 


\section{Acknowledgements}

The report / article reflects the results of the work on the project No. 21 - FOZZG - 02 "Creating methodological and scientific resources for optimizing the module Practical basics of nursing and midwifery care in the virtual educational environment", funded by the Research Fund of the University of Ruse.

\section{References}

[1]. Arkkelin, D. (2014). Using SPSS to understand research and data analysis. Psychology Curricular Materials. Book 1.

[2]. Beloev, H., Smrikarov, A., Ivanova, A., Vassilev, T., Georgiev, T., Smrikarova, S., ... \& Zlatarov, P. (2020, June). A Vision of the University of the Future. In Proceedings of the 21st International Conference on Computer Systems and Technologies' 20 (pp. 307312).

[3]. Cohen, P., West, S. G., \& Aiken, L. S. (2014). Applied multiple regression/correlation analysis for the behavioral sciences. Psychology press.

[4]. Cruz-Cano, R., \& Lee, M. L. T. (2014). Fast regularized canonical correlation analysis. Computational Statistics \& Data Analysis, 70, 88-100.

[5]. Gao, C., Ma, Z., Ren, Z., \& Zhou, H. H. (2015). Minimax estimation in sparse canonical correlation analysis. The Annals of Statistics, 43(5), 2168-2197.

[6]. Georgieva-Tsaneva, G., \& Serbezova, I. (2020). Virtual Reality and Serious Games Using in Distance Learning in Medicine in Bulgaria. International Journal of Emerging Technologies in Learning (iJET), 15(19), 223-230.

[7]. Hinton, P., McMurray, I., \& Brownlow, C. (2014). SPSS explained. Routledge.
[8]. Koleva, G., Georgieva, D., \& Hristova, I. (2019). Pedagogical observation of students for applying scales of assessing clinical states and symptoms in palliative nursing care. International Journal of Medical Physiology, 4.

[9]. Landau, S., \& Everitt, B. S. (2004). Chapter 9: Logistic Regression: Who Survived the Sinking of the Titanic?. A Handbook of Statistical Analyses using SPSS.

[10]. Manukova-Marinova, A., Sokolov, T., \& Marinov, M. (2020). Algorithm and Software System for Treatment Application of Platelet-Rich Plasma on Problematic Skin Wounds. Cybernetics and Information Technologies, 20(1), 129-137.

[11]. Miteva, K. (2015). Clinical Practice Organizational Aspects in the Training of Students of Speciality "Midwife". Trakia Journal of Sciences, 13(3), 263.

[12]. O'Keeffe, V., Boyd, C., Phillips, C., \& Oppert, M. (2021). Creating safety in care: Student nurses' perspectives. Applied Ergonomics, 90, 103248.

[13]. Sarsar, F., Kale, Ö. A., Andiç-Çakır, Ö., Gueorguiev, T., Evstatiev, B., Georgieva, T., ... \& van Leeuwen, M. (2021). Multicultural investigation of the students' acceptance of using digital learning materials in laboratory classes. Computer Applications in Engineering Education, 29(4), 883-896.

[14]. Sokolov, T., Manukova, A., Kovachev, V., \& Kovachev, M. (2020). Treatment of Problematic Skin Wounds Based on The Platelet-Rich Plasma Method. Our Own Algorithms for Application. Journal of IMAB-Annual Proceeding Scientific Papers, 26(4), 3436-3442. doi: 10.5272/jimab.2020264.3436

[15]. Zlatarov, P., Ivanova, G., Baeva, D., \& Antonova, D. (2018, September). Adaptive Software System for Optimization of the Admission and Management Process for Doctoral Students. In Proceedings of the Computational Methods in Systems and Software (pp. 323-332). Springer, Cham. 